\title{
Identificação das variáveis que influenciam na qualidade do trabalho - estudo de caso da Micrológica Informática em Formosa - Goiás
}

\author{
Identification of the variables that influence the quality of work - case study of Computer \\ Micrology in Formosa - Goiás \\ Identificación de las variables que influyen en la calidad del trabajo - estudio de caso de Micrología \\ Informática en Formosa - Goiás
}

\author{
José Carlos Guimarães Junior \\ ORCID: https://orcid.org/0000-0002-8233-2628 \\ Universidade do Estado do Amazonas, Brasil \\ E-mail: Profjc65@hotmail.com \\ Aline dos Santos Moreira De Carvalho \\ ORCID: https://orcid.org/0000-0001-9965-9566 \\ Universidad Columbia Del Paraguay, Paraguai \\ E-mail: bioaline2017@yahoo.com \\ Breno Giovanni Adaid-Castro \\ ORCID: https://orcid.org/0000-0002-9856-4263 \\ Universidade de Brasília, Brasil \\ E-mail: Brenoadaid@gmail.com \\ Evaldo Freires de Carvalho \\ ORCID: https://orcid.org/0000-0002-4539-8441 \\ Universidad Columbia Del Paraguay, Paraguai \\ E-mail: evaldofreires@hotmailcom
}

\begin{abstract}
Resumo
O treinamento é uma das ferramentas de aprimoramento das habilidades e competências dos profissionais que atuam nas diversas organizações; assim a empresa tem melhores condições técnicas de desenvolverem suas atividades produzindo resultados positivos. O objetivo geral da presente pesquisa foi identificar a necessidade de treinamento dos funcionários da empresa Micrológica, em Formosa-GO. A metodologia utilizada foi a aplicação de um questionário oferecidos aos colaboradores da referida empresa durante o período de 10 dias, onde todos tiveram acesso ao instrumento de pesquisa; e diante dos dados obtidos, foi possível identificar as variáveis que afetam todo o processo de produção, além de oferecer condições para que possam aprimorar suas atividades.
\end{abstract}

Palavras-chave: Treinamento; Desenvolvimento; Desempenho profissional.

\begin{abstract}
Training is one of the tools for improving the skills and competences of professionals who work in different organizations; thus the company has better technical conditions to develop its activities producing positive results. The general objective of this research was to identify the need for training employees of the company Micrológica, in Formosa-GO. The methodology used was the application of a questionnaire offered to employees of that company during a period of 10 days, where everyone had access to the research instrument; and given the data obtained, it was possible to identify the variables that affect the entire production process, in addition to offering conditions for them to improve their activities.
\end{abstract}

Keywords: Training; Development; Professional performance.

\section{Resumen}

La formación es una de las herramientas para mejorar las habilidades y competencias de los profesionales que trabajan en diferentes organizaciones; de esta forma la empresa cuenta con mejores condiciones técnicas para desarrollar sus actividades produciendo resultados positivos. El objetivo general de esta investigación fue identificar la necesidad de formar a los empleados de la empresa Micrológica, en Formosa-GO. La metodología utilizada fue la aplicación de un cuestionario ofrecido a los empleados de esa empresa durante un período de 10 días, donde todos tenían acceso al instrumento de investigación; y dados los datos obtenidos, fue posible identificar las variables que inciden en todo el proceso productivo, además de ofrecerles condiciones para mejorar sus actividades.

Palabras clave: Entrenamiento; Desarrollo; Rendimiento profesional. 


\section{Introdução}

O tema motivação se caracteriza como amplo e oferece uma complexidade importante e tem sido assunto frequente nas principais discussões nas organizações, não obstante a outros temas também (Pecequilo, 2017).A variável recursos humanos é presente em todos os níveis estratificados da organização, sendo necessário a frequente avaliação dos pares que atuam nos diversos setores, de maneira que não os tornem inoperantes e desatualizados; assim, torna-se imprescindível desenvolver processos que atraiam e ofereçam condições para que retenham esses profissionais nas empresas (Reis, 2021).

Dessa forma, oferecendo condições importantes de treinamento e aperfeiçoamento para esses colaboradores, onde sua motivação é exacerbada produzindo de maneira mais eficiente e eficaz. A motivação é um instinto, onde podem ser inerentes ao ser humanos ou serem provocadas através de ações externas, como um incentivo par se fazer um curso, por exemplo (Reis, 2021).

O evento da Revolução Industrial, em suas duas fases, concretizou-se no aspecto motivacional, ao incentivo aos trabalhadores em produzirem mais de maneira que recebessem uma motivação para que recebessem uma remuneração mais importante, onde a quantidade produzida era a forma de melhorar suas rendas (De Lima, 2017).

Entretanto, a revolução industrial proporcionou investimentos cada vez mais significativos e tiveram o objetivo de aumentar a eficiência e a eficácia dos processos produtivos que por sua vez, ofereceriam condições para que os trabalhadores fossem melhor remunerados, variando de acordo com a sua produção (De Lima, 2017).

Essa nova realidade proporcionou uma nova fase do que diz respeito a forma e desempenho nas atividades rotineiras das organizações, porém cabe ressaltar que não essas melhorias nos processos produtivos não se ativeram apenas a quantidade de produtos produzidos, mas também ao aspecto qualidade; assim, a necessidade de treinamento dos trabalhadores torna-se uma necessidade, em um primeiro momento, incorporando-se ao processo natural da organização (Torquato, 2020).

Assim, os gestores dessas empresas tiveram que obrigatoriamente tiveram que atentar ao desenvolvimento de um plano de carreira e de remuneração que fosse condizente com as atividades desenvolvidas e as características profissionais que cada trabalhadora das suas organizações (Camilo; Ivelise; MYRT, 2021).

\section{Treinamento e sua importância nas empresas}

Grande parte dos profissionais busca colocação no mercado de trabalho tendo como referência a remuneração oferecida em um primeiro momento e, posteriormente, os benefícios oferecidos.

Drucker (1977 apud Bergamini 1997, p. 21), ressalta que este tipo de tratamento se torna perverso, analisando que os incentivos econômicos vão se tornando direitos, em vez de recompensas. Elton Mayo (apud Bergamini 1997, p. 21), com uma segunda proposta traz a importância de considerar a pessoa na sua totalidade.

A estratégia administrativa deveria promover o reconhecimento do valor de cada pessoa, alem de buscar, de forma muito especial, a satisfação de suas necessidades sociais. Deci (1996 apud Bergamini 1997, p. 33); da o exemplo de que: ”A maneira mais fundamental e útil de pensar a respeito desse assunto envolvesse a aceitação do conceito de motivação intrínseca, que se refere ao processo de desenvolver uma atividade pelo prazer que ela mesma proporciona, isto é, desenvolver uma atividade pela recompensa inerente a essa mesma atividade”. Essa teoria vem de encontro com as necessidades internas que motivam o comportamento de cada indivíduo.

Com isso as pessoas buscam reduzir ou mesmo satisfazer essas necessidades de determinada maneira que veremos na figura (1) abaixo. 
Figura 1: Um Modelo de Teoria de Conteúdo da Motivação

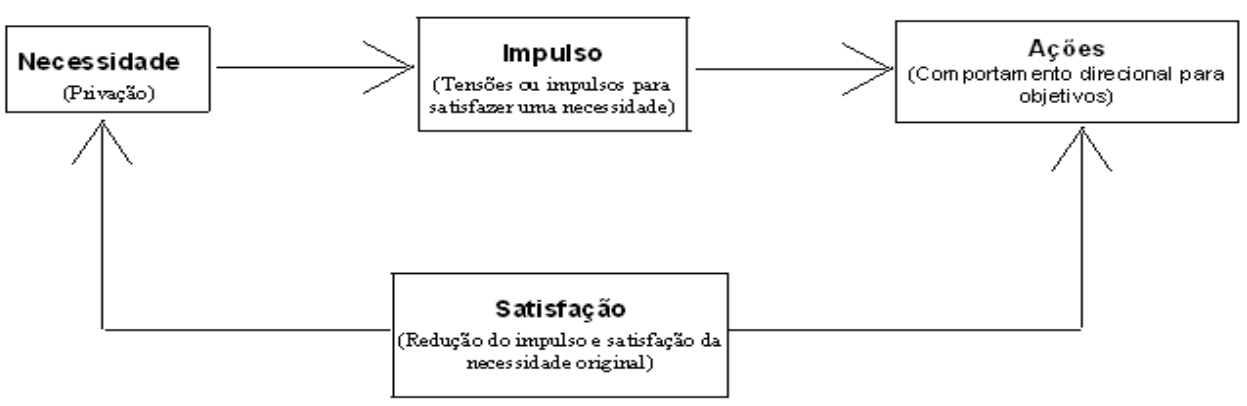

Fonte: Stoner, Freeman (1999.p.324).

Maslow (1970 apud Bergamini 1997, p. 71), propõe o seguinte referencial: "Praticamente, todas as teorias históricas e contemporâneas de motivação se unem na consideração das necessidades, impulso e estados modificadores, em geral, como importunos, irritantes, indesejáveis, desagradáveis, enfim, como algo de que devemos nos livrar.

O comportamento motivado, a procura de metas e de respostas são metodologias de trabalho que buscam a redução de variáveis que afetem o desempenho dos trabalhadores, procurando aumentar a motivação que esses são induzidos durante a sua jornada de trabalho. Essas posturas são assumidas de forma explícitas nos processos motivacionais dentro das organizações e tem como resultados a redução de tensão; redução de impulso e de ansiedade.

Desde a sua divulgação há mais de 30 anos, a teoria de Maslow, tornou-se uma das teorias mais populares sobre motivação dentro do referencial da literatura sobre comportamento organizacional. De acordo com Stoner (1999, p. 302), motivação "é o conjunto de conhecimentos importantes, como normas, valores, atitudes e crenças, compartilhados pelos membros da organização".

Contudo a Motivação vem de encontro com a cultura da organização e a sociedade que esta organização está localizada, essa cultura molda o comportamento e as expectativas de cada indivíduo. Ainda o mesmo autor refere-se a cultura organizacional, com, "quando a cultura de uma organização é compatível com sua estratégia, a implementação de estratégia fica consideravelmente facilitada." Com isso Stoner (1999, p.165) diz [...] é impossível implementar com sucesso uma estratégia que contradiga a cultura organizacional.

A empresa Micrológica Informática Ltda está localizada na cidade de Formosa-GO, e é uma empresa familiar que é gerida pelo seu proprietário, possui em seu quadro um total de quatro funcionários.

Tendo iniciado suas atividades, em 2001 buscando ocupar um percentual de mercado no cenário que compõe as empresas provedoras e acesso à internet na cidade de Formosa, focando, principalmente o diferencial de qualidade no atendimento aos seus clientes.

Ao longo de seus cinco anos de existência, tornou-se, não somente um dos 4 maiores provedores de acesso à internet na região, mas também uma empresa especializada em soluções de informática para as diversas demandas existentes na cidade.

Hoje, os clientes encontram uma empresa jovem, com vocação para inovar e expandir suas atividades; transpondo obstáculos difíceis em uma primeira visão, mas que se tornaram acessíveis pela disposição de seus proprietários e de seu corpo de colaboradores, que tem tiveram vontade de tornar-se uma empresa de referência no mercado de Formosa e região.

Oferecendo soluções de informática para todas as demandas existentes nesse mercado, utilizando-se de tecnologias de ponta, prestando serviços com extrema qualidade e consideração aos seus clientes, tem hoje em sua carteira de parceiros, cerca de 200 clientes fidelizados que se tornaram advogados da marca Micrológica. Contando com uma equipe diversificada, com 
especialistas em rede, software e hardware, oferecendo serviços que vão desde a configuração de um computador pessoal até complexos sistemas informatizados para grandes empresas, e ainda promovendo um atendimento diferenciado para cada cliente em especial, além de ter em seu quadro de funcionários altamente capacitados, conta com uma capacidade tecnológica bastante importante.

Devido à qualificação técnica dos nossos funcionários, conseguimos fornecer aos nossos clientes os mais variados tipos de serviços, desde o acesso à internet, desenvolvimento de sistemas e redes até a configuração e manutenção de servidores.

Para melhor compreender a real situação da empresa, realizamos a análise swot, onde identificamos as variáveis que são fundamentais para melhor expressar a situação da organização que passamos a citá-los a seguir:

Pontos fortes: Concorrência praticamente inexistente ou que, hoje, não representam muito na parcela de participação do mercado.

Pontos fracos: Observou-se que a empresa tem grande dificuldade de encontrar profissionais habilitados em desempenhar as funções técnicas que necessárias a uma boa prestação de serviços.

Quanto as ameaças identificamos a oferta pelo mercado de linhas de crédito e para capital de giro com condições bem atraentes, e assim, fazem com que surjam novos empreendedores, com capacidade maior de articulação no mercado de trabalho, seja com fornecedores ou clientes.

Quanto as oportunidades, o mercado oferece oferta de inúmeras empresas que prestam serviços em vários segmentos.

\section{Métodos e Procedimentos}

A pesquisa foi realizada de acordo com uma visão explicativa, sendo observado no local de estudo as variações de comportamento e decisões que afetam a motivação de cada indivíduo no trabalho, e o instrumento utilizado para a realização da pesquisa foi um questionário com perguntas fechadas. A amostra da pesquisa foi de 8(oito) funcionários, que representam o total de colaboradores da empresa e, para a identificação das variáveis, fez-se necessário a aplicação de questionário fechado.

\section{Resultados e Discussões}

No percentual de $75 \%$ dos funcionários sentirem-se motivados em trabalhar na empresa, $25 \%$ desse total, ainda continua na empresa, porém não considera que as condições de trabalho sejam satisfatórias, a ponto de afirmar que se sentem motivados a ir trabalhar todos os dias.

A sugestão que fica nessa análise, é no sentido de procurar identificar quais variáveis estão afetando esse grau de satisfação motivacional desses $25 \%$ que apresentaram esse tipo de afirmação. Após a identificação desses motivos, sugere-se que sejam revertidos em satisfação e, em última instância, demitir esses colaboradores.

A maioria dos funcionários tem a percepção de que existe a percepção de crescimento dentro da estrutura da empresa. Percentualmente, podemos afirmar que todo o colaborador tem alguma perspectiva de crescimento dentro da empresa, mas se analisarmos pela quantidade de funcionários, ainda existe 1(um) funcionário que não vê perspectiva alguma de crescimento.

Além disso o fator motivação, todos os funcionários sentem-se motivados e habilitados em assumir outras funções mais estratégicas, mas que não, necessariamente, mais importantes. Nessa análise é importante que se defina quais as funções que em futuro próximo poderá ser oferecida a esses funcionários (se na verdade será), pois, percebeu-se, através de conversa informal com o proprietário da empresa que dificilmente alguma função estratégica deixara de ser comandada pela sua pessoa. 
Apenas quatro funcionários estão trabalhando na função que efetivamente foram contratados e apenas dois estão nas suas funções. Quanto ao aspecto da não satisfação dos funcionários no viés remuneração, identificamos que $75 \%$ dos entrevistados não estão satisfeitos com seus salários.

\section{Propostas e Sugestões}

Ao melhorar a autoestima da equipe, o crescimento na produtividade e na qualidade do trabalho será natural e algumas sugestões, porém a empresa deve oferecer mais do que isso.

Permitir horários flexíveis. Muitas funções não precisam ser realizadas estritamente no horário comercial. Os funcionários serão muito gratos se tiverem flexibilidade para realizar outras atividades pessoais durante parte do dia, e administrar o tempo conforme suas possibilidades.

Permitir o trabalho remoto. Da mesma forma, há atividades que podem ser realizadas na casa do funcionário, uma conexão à internet em banda larga não tem um custo alto, e ferramentas de colaboração à distância estão cada vez mais elaboradas (e baratas). Muitos profissionais darão preferência a sua empresa pelo fato de permitir trabalho remoto, mesmo que seja somente durante alguns dias da semana.

Avaliar regularmente o desempenho dos funcionários. Definir um processo regular de avaliação do trabalho de cada um, e dê um feedback claro e objetivo sobre os pontos fortes e os que precisam de melhoria. Os bons profissionais verão isto como algo muito positivo, já que sempre perseguem o aperfeiçoamento de suas atividades.

Estimular os funcionários a realizar tarefas variadas. A palavra chave aqui é estimule (não obrigue). Deixar claro que os objetivos desta iniciativa são o aumento do conhecimento de cada um e a redução da monotonia na função.

Permitir que os funcionários ajustem, decorem e melhorem sua área de trabalho. Não impor regras rígidas de organização e estética. Se cada um criar seu próprio espaço de trabalho (dentro de certos limites), se sentirá mais à vontade durante o dia e a produtividade aumentará.

Organizar oportunidades de socialização. Isto deve ser feito durante o almoço, ou depois do trabalho. A amizade entre os funcionários aumentará a união da equipe, e isso se traduzirá em melhor produtividade e qualidade. Não fique isolado do grupo, saiba ser amigo mantendo a posição que a liderança exige.

Mostrar o caminho para crescer na empresa. Em um negócio pequeno, o caminho de crescimento pode ser pouco claro. O líder deve mostrar qual é este caminho, e buscar oportunidades de promoção dos melhores funcionários para mostrar que o bom desempenho é realmente valorizado.

Tenha uma política de portas abertas. Permitir que as dúvidas e questionamentos sejam expostos abertamente, e responda o melhor possível a cada um. Levar em conta as sugestões dos funcionários e implemente com seriedade as melhores idéias.

Existem limites da aplicação das propostas que foram identificados quando da realização da pesquisa, observou-se com uma particularidade bastante expressiva o comportamento do proprietário da empresa, objeto desse estudo, e percebe-se que alguns fatores, tais, como: a baixa formação acadêmica do proprietário, falta de aptidão para o trato com seus subordinados, dependência técnica de funcionários para resolver os problemas da empresa,falta de incentivo aos funcionários, seja, pela questão salarial ou mesmo fornecer as mínimas condições de trabalho, seja na própria empresa, seja os serviços externos. Todos esses fatores são considerados obstáculos fortes para a implementação e, consequentemente, uma melhoria nos resultados da empresa. 
A sugestão que fica nesse trabalho, no sentido de derrubar essas barreiras, é que o proprietário da empresa, tenha bom senso e iniciativa de perceber que sua postura em relação aos fatores citados acima, fazem com que alguns resultados da empresa se tornem menores do que o previsto.

\section{Considerações Finais}

Fazendo-se uma análise bem sistemática, no intuito de não se fazer repetitivo, através dos objetivos propostos nessa pesquisa, percebeu-se que a identificação e as proposições previstas no item sugestões, desde que sejam seguidas da forma que foram propostas, permitirão que a empresa ganhe um novo rumo nas suas expectativas de crescimento dentro do mercado da cidade de Formosa e, futuramente, na região chamada de entorno, permitindo dessa forma uma grande expansão e melhoria nos serviços prestados.

Da mesma forma, cabe ressaltar que, as sugestões citadas, devem ser implementadas num período de tempo mais breve possível e é sabedouro também que os resultados surgirão em um período de médio e longo prazo, desde que todas as sugestões sejam implementadas e acompanhadas.

\section{Referências}

Bergamini, C. W. (1997). Motivação nas organizações. (4a ed.), Atlas

Broxado, S. (2001). A verdadeira motivação na empresa; entendendo a psicologia organizacional e dicas para a motivação no dia-a-dia das empresas. Qualitymark Ed.

Camilo, J.; Ivelise, F., \& Myrt, T. de S. C. (2021). Gestão de pessoas: práticas de recrutamento e seleção por competências. Editora Senac São Paulo.

De Lima, E. C.; \& Calisto, R. de O. N. (2017): Revolução Industrial: considerações sobre o pioneirismo industrial inglês. Revista Espaço Acadêmic. 17(194). 102-113.

José, L. H. de P. (2001). Motivando os funcionários na pequena empresa. <http://www.ogerente.com>.

Gil, A. C. (2002). Como elaborar projetos de pesquisa. (4a ed.), Atlas

Kanaane, R. \& Ortigoso, S. A. F. (2001). Manual de treinamento e desenvolvimento do potencial humano. Atlas

Kotler, P. (1998). Administração de Marketing: análise, planejamento, implementação e controle. (5a ed.), Atlas

Lévy-Leboyer, C. (1994). A crise das motivações. Atlas

Marras, J. P. (2000). Administração de recursos humanos. (4a ed.), Futura

Pecequilo, C. S. (2017). Introdução às relações internacionais: temas, atores e visões. Editora Vozes Limitada

Reis, J. R. A. (2021). Estratégia e práticas de liderança na Gestão de Recursos Humanos. Estudos de caso de empresas. Dissertação de mestrado, Universidade de Évora

Stoner, J. A. F \& Freeman, R. E. (1999). Administração. (5a ed.), LTC

Schutz, E. (1999). Motivação para a qualidade: pensamento positivo e automotivação. (3a ed.), Insular

Torquato, G. (2020). Cultura-Poder-Comunicação-Crise e Imagem. Cengage Learning 